\title{
Hubert De Phalese, Les bons contes et les bons mots de «Gil Blas»
}

Franco Piva

\section{(2) OpenEdition}

1 Journals

Édition électronique

URL : https://journals.openedition.org/studifrancesi/39408

DOI : $10.4000 /$ studifrancesi.39408

ISSN : 2427-5856

Éditeur

Rosenberg \& Sellier

Édition imprimée

Date de publication : 1 décembre 2004

Pagination : 372-373

ISSN : 0039-2944

\section{Référence électronique}

Franco Piva, "Hubert De Phalese, Les bons contes et les bons mots de "Gil Blas» », Studi Francesi [En ligne], 143 (XLVIII | II) | 2004, mis en ligne le 30 novembre 2015, consulté le 19 mai 2021. URL : http:// journals.openedition.org/studifrancesi/39408 ; DOI : https://doi.org/10.4000/studifrancesi.39408

Ce document a été généré automatiquement le 19 mai 2021.

\section{cc)}

Studi Francesi è distribuita con Licenza Creative Commons Attribuzione - Non commerciale - Non opere derivate 4.0 Internazionale. 


\title{
Hubert De Phalese, Les bons contes et les bons mots de «Gil Blas»
}

\author{
Franco Piva
}

\section{RÉFÉRENCE}

HUBERT DE PHALESE, Les bons contes et les bons mots de «Gil Blas», Saint-Genouph, Librairie A.-G. Nizet, 2002 (Coll. «CAP’AGREG», n. 14), pp. 159.

«Je remarquai entre autres choses, qu'il aimait les plaisanteries, les bons contes et les bons mots. Je me réglai là-dessus. J'écrivais tous les matins sur mes tablettes les histoires que je voulais lui conter dans la journée». C'est ainsi que Raphael, le picaro devenu tour à tour riche renégat à Alger puis favori du grand-duc de Florence, fait la cour à son maître. Il n'en a d'ailluers pas l'exclusivité car «les bons mots et les bons contes» constituent, par certains aspects, l'essentiel du roman de Lesage. Hubert de Phalèse («nom collectif adopté par une équipe d'enseignants-chercheurs qui utilisent les nouvelles technologies dans leurs travaux et souhaitent en faciliter l'accès aux littéraires, à tous les niveaux du système éducatif») s'est proposé de «prendre au mot» le roman de Lesage, dans la conviction que le parti pris de lecture consistant à «souligner dans Gil Blas la dimension textuelle de la démarche romanesque» faciliterait l'approche d'une œuvre qui pourrait, autrement, «dérouter par le foisonnement des narrateurs, des références, des épisodes, des sources».

2 Le roman est d'abord situé dans une tradition littéraire, qui resulte d'ailleurs moins espagnole que française. On montre ensuite sur queis matériaux textueis préexistants Lesage s'est appuyé. Puis on retrace la «fortune» du roman. L'étude du paratexte, un tableau général des chapitres, avec un essai de chronologie générale de la narration, permet de poser concrètement la question du réalisme. L'approche stylistique du vocabulaire du roman permet enfin de «jauger les originalités, les particularités, les spécificités de l'œuvre et de ses différentes parties». Suit un parcours thématique (la route, le costume, le théâtre, les médecins, l'argent, le comique, la sagesse) comme 
autant de «leçons», d'itinéraires permettant de croiser et recroiser les discours du roman pour qu'ils fassent sens. Un glossaire-concordance fournit des repères linguistiques et encyclopédiques pour une meilleure compréhension littérale d'un texte «à la simplicité souvent trompeuse». Une bibliographie suggère enfin des lectures complémentaires.

3 Pensé en principe pour les candidats du CAPES et de l'agrégation, ce volume peut en fait résulter très utile pour tout lecteur de Gil Blas: riche en données intéressantes, en suggestions originales, en perspectives nouvelles, la lecture du chef-d' œuvre de Lesage que nous propose Hubert de Phalèse ne peut manquer de susciter de nouvelles questions à propos d'un texte que la critique, d'un côte, a sans doute un peu trop negligé, d'un autre côte, a lu selon des perspectives peut-être un peu trop traditionnelles. 